\title{
Photoredox Catalysis: A Mild, Operationally Simple Approach to the Synthesis of $\alpha$-Trifluoromethyl Carbonyl Compounds
}

\author{
Phong V. Pham, David A. Nagib, and David W. C. MacMillan[Prof.] \\ ${ }^{*}$ Merck Center for Catalysis at Princeton University Washington Road, Princeton NJ 08544-1009 \\ (USA)
}

\section{Keywords}

enolsilanes; photoredox catalysis; $\alpha$-perfluoroalkylation; $\alpha$-trifluoromethylation

\begin{abstract}
The unique physical and chemical advantages conferred by the $\mathrm{C}-\mathrm{F}$ bond have led to the broad exploitation of this motif throughout the pharmaceutical, ${ }^{[1]}$ materials, ${ }^{[2]}$ and agrochemical ${ }^{[3]}$ sectors. In drug design, for instance, incorporation of polyfluorinated alkyl groups, such as $\mathrm{CF}_{3}$ moieties, can profoundly impact the activity, metabolic stability, lipophilicity, and bioavailability of lead compounds. ${ }^{[1,4]}$ Not surprisingly, the development of methods for the production of carbonyl-based synthons bearing $\alpha-\mathrm{CF}_{3}$ substitution has emerged as a central objective in the field of chemical synthesis. Although important recent advances have been made toward this goal, there are currently few operationally simple methods for the conversion of enolates (or enolate equivalents) to $\alpha$-trifluoromethylated carbonyl motifs. Standard alkylation methods are generally not productive, due to the negative polarization of the trifluoromethyl moiety, thus specially tailored reagents have been developed to furnish an electrophilic $\mathrm{CF}_{3}$ equivalent. ${ }^{[5]}$ Alternatively, in recent years, a set of radical $\left(\mathrm{Et}_{3} \mathrm{~B} / \mathrm{O}_{2}\right)$ and organometallic (Rh-catalyzed) approaches have been pursued to introduce the trifluoromethyl species through enolate derivatives. ${ }^{[6,7]}$ While these methods offer significant progress toward solving the " $\alpha-\mathrm{CF}_{3}$ carbonyl problem", issues of substrate scope, cryogenic temperatures, and regioselectivity of $\mathrm{CF}_{3}$ incorporation remain prominent concerns. Herein, we describe a mild, operationally simple, room temperature method for the $\alpha$-trifluoromethylation of enolsilanes, achieved through application of our recently described photoredox catalysis strategy. ${ }^{[8,9]}$ Furthermore, a one-pot protocol has been developed to enable the rapid fluoroalkylation of ketones, esters, and amides, without the isolation of pre-generated enolsilane intermediates.
\end{abstract}

Design plan: Recently, our laboratory established a new activation mode for the direct enantioselective alkylation of aldehydes. Termed photoredox organocatalysis, this novel strategy exploits a synergistic relationship between chiral amine and organometallic photoredox catalysts as a means to access electrophilic alkyl radicals that rapidly combine with enamines under ambient conditions. ${ }^{[8]}$ We postulated that the mechanistic logic underlying photoredox catalysis could be extended to devise a simple yet general approach to the $\alpha-$

(C) 2011 Wiley-VCH Verlag GmbH \& Co. KGaA, Weinheim

Fax: (+1)609-258-5922 dmacmill@ princeton.edu.

Supporting information for this article is available on the WWW under http://dx.doi.org/10.1002/anie.201101861. 


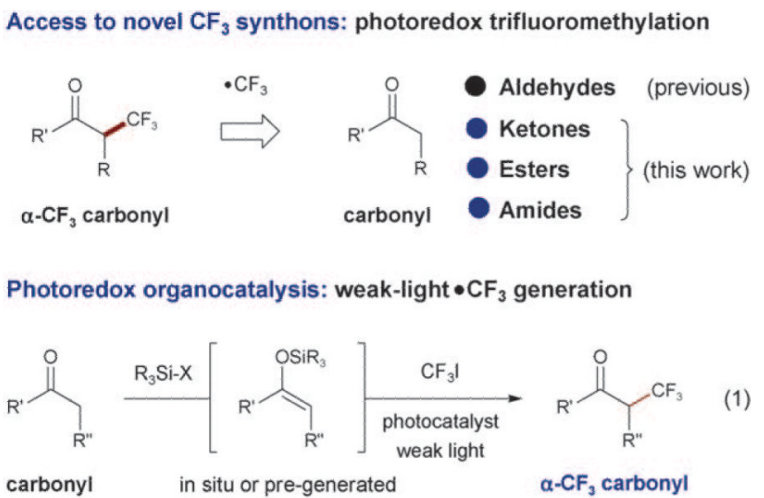

trifluoromethylation of a range of enolates or enolate equivalents [Eq. (1)]. In this context, we elected to employ enolsilanes and silylketene acetals as suitable enolic substrates, given their synthetic accessibility and well-established capacity to combine with electrophilic coupling partners. ${ }^{[10]}$ As outlined in Scheme 1, we proposed that photoexcitation of $\left[\mathrm{Ru}(\mathrm{bpy})_{3}\right]^{2+}(\mathbf{1})$ using a household light bulb, followed by single-electron reduction of $\mathbf{2}$ should rapidly generate $\left[\mathrm{Ru}-(\mathrm{bpy})_{3}\right]^{+}(\mathbf{3}) \cdot{ }^{[11]}$ As we have previously described, this potent one-electron reductant can readily participate in single-electron transfer (SET) with $\mathrm{CF}_{3} \mathrm{I}$ to generate the electrophilic trifluoromethyl radical, which we hoped would rapidly combine with enolsilane 4 to furnish $\alpha$-silyloxy radical $\mathbf{5}$. The oxidation potential of $\mathbf{5}$ is anticipated to be sufficiently low to allow for facile oxidation by $*\left[\operatorname{Ru}(\mathrm{bpy})_{3}\right]^{2+}(2)\left(E_{1 / 2 \text { red }}=0.79 \mathrm{~V}\right.$ vs. $\mathrm{SCE}$ in $\mathrm{MeCN})^{[12]}$ to generate silyloxocarbenium $\mathbf{6}$, an unstable species that should rapidly undergo hydrolysis to yield the desired $\alpha$-trifluoromethylated carbonyl product. ${ }^{[13]}$

As shown in Table 1, our initial studies confirmed the feasibility of the proposed trifluoromethylation when the tert-butyldimethylsilyl (TBS) substituted enolsilane $\mathbf{7}$ was exposed to $\mathrm{CF}_{3} \mathrm{I}, 0.5 \mathrm{~mol} \%$ [Ru(bpy $\left.)_{3} \mathrm{Cl}_{2}\right](\mathbf{1})$, and a $26 \mathrm{~W}$ household fluorescent lamp in the presence of 1.5 equivalents of $\mathrm{Et}_{3} \mathrm{~N}$ in DMF (entry 1, 35\% yield). Importantly, no alkylation was observed when either amine base, $\left[\mathrm{Ru}(\mathrm{bpy})_{3} \mathrm{Cl}_{2}\right]$ catalyst, or light was excluded from this protocol (entries 2-4). Early investigations further revealed the importance of employing a tertiary amine base to serve both as a sacrificial reductant and to scavenge the deleterious HI byproduct. ${ }^{[11,14,15]}$ With this in mind, the reaction efficiency was further enhanced by 1) the use of a more reducing and more basic amine base, $i_{2}{ }_{2} \mathrm{NEt}, 2$ ) incorporation of a less acid-labile silyl group (TIPS) on the enolsilane substrate, and 3) the addition of water to aid in the capture of the putative silyl cation intermediate (entries 5-8, $45-94 \%$ yield). Indeed, the observed levels of reaction efficiency using $0.5 \mathrm{~mol} \%$ $\left[\mathrm{Ru}(\mathrm{bpy})_{3} \mathrm{Cl}_{2}\right]$ (1) with triisopropylsilyl-substituted enolsilane $\mathbf{7}$ in the presence of THF- $\mathrm{H}_{2} \mathrm{O}$ and $i \mathrm{Pr}_{2} \mathrm{NEt}$, established these conditions as optimal for further exploration.

As revealed in Table 2, a broad range of ketone-derived enolsilanes that exhibit diverse electronic and steric properties readily participate in this new photoredox trifluoromethylation protocol. Specifically, this fluoroalkylation strategy is tolerant to enolsilane coupling partners that incorporate arenes, nitriles, and halogens (entries 1-7, 6692\%), as well as sulfides, ethers, and carbamates (entries 10-13, 59-73\%). Moreover, sterically demanding substrates (entry 15 , adamantyl, $84 \%$ ), as well as large ring sizes (entry $14,68 \%$ ), are accommodated with minimal impact on yield. Intriguingly, we observe an important structural bifurcation in that TIPS-derived enolsilanes of aromatic ketones (entries $1-7,66-92 \%$ yield) typically achieve higher yields, whereas for aliphatic ketones, TESsubstituted enolsilanes provide generically higher yields in this trifluoromethylation protocol 
(entries $8-15,59-84 \%$ yield). Interestingly, this trend is also maintained in the formation of quaternary carbon centers (entry $16,76 \%$ yield).

We next sought to examine the applicability of this trifluoromethylation strategy to other carbonyl classes, specifically silylketene acetal and N,O-acetal substrates derived from ester and amide synthons (Table 3). To our initial surprise, we observed that silylketene acetals of $\delta$-valerolactone underwent rapid alkylation in the presence of the $26 \mathrm{~W}$ fluorescent light, without the requirement of the photoredox catalyst $\left[\mathrm{Ru}(\mathrm{bpy})_{3} \mathrm{Cl}_{2}\right]$ (entry $1,85 \%$ yield). In this case we assume that a photon-induced charge-transfer complex mechanism is likely operative. ${ }^{[16]}$ Notably, these photoredox catalyst-free trifluoromethylation conditions can be successfully utilized with a range of silylketene acetals and N,O-acetals, provided monosubstituted enols are employed (entries 2 and 4, 76-86\% yield). Indeed, the more sterically demanding disubstituted silylketene acetals were found to be significantly less activated toward $\alpha$-trifluoromethylation using this alternative light-induced charge-transfer mechanism, providing only moderate alkylation yields after extended reaction times $(24 \mathrm{~h})$. Fortunately, high levels of trifluoromethylation efficiency could be re-established for these structurally encumbered substrates using our standard $\left[\mathrm{Ru}(\mathrm{bpy})_{3} \mathrm{Cl}_{2}\right]$-catalyzed photoredox conditions (entries 3 and $5,74-84 \%$ yield).

As a demonstration of the synthetic utility of our catalytic photoredox protocol, we have developed a facile, two-step, one-flask procedure for the direct $\alpha$-trifluoromethylation of a broad range of carbonyl-containing substrates (Table 4). As shown, the enolsilane is first formed in situ in the presence of photocatalyst $\mathbf{1}$, silylating agent, and an appropriate base. The resultant enolsilane (without isolation or purification) is then exposed to $\alpha$ trifluoromethylation conditions to generate the target $\alpha$-alkylation adduct in a single reaction vessel. This procedure was found to be applicable to ketone, ester, and amide substrates, delivering the desired products with good overall efficiency (entries 1-3, 67-78\% yield).

Importantly, this one-pot protocol is also amenable to a range of $\alpha$-fluoroalkylations. When subjected to the outlined procedure, ethyl caprylate underwent perfluoroalkylation ( $n$-propyl and isopropyl) and difluoroalkylation with excellent levels of reaction efficiency (entries 4$6,75-92 \%$ yield).

In summary, we have introduced a new photoredox-based method that allows for facile $\alpha$ trifluoromethylation of enolsilanes, silylketene acetals and N,O-acetals derived from a broad range of ketone, ester, and amide substrates. Moreover, we have devised a one-pot protocol that enables the rapid and trivial installation of the trifluoromethyl moiety, as well as other fluoroalkyl groups, directly to a wide array of carbonyl systems. We expect this novel protocol to be of broad utility in the synthesis of biologically active organofluorine containing medicinal agents.

\section{References}

[1]. Filler, R.; Kobayashi, Y.; Yagupolskii, LM., editors. Organofluorine Compounds in Medicinal Chemistry \& Biomedical Applications. Elsevier; Amsterdam: 1993.

[2]. Hiyama, T.; Yamamoto, H.; Hiyama, T.; Kanie, K.; Kusumoto, T.; Morizawa, Y.; Shimzu, M., editors. Organofluorine Compounds: Chemistry and Application. Springer; Berlin: 2000. p. 183-234.

[3]. Banks, RE.; Smart, BE.; Tatlow, CJ., editors. Organofluorine Chemistry, Principles and Comercial Applications. Springer; New York: 1994. p. 237-262.

[4]. a) Purser S, Moore PR, Swallow S, Gouverneur V. Chem. Soc. Rev.. 2008; 37:320-330. [PubMed: 18197348] b) Müller K, Faeh C, Diederich F. Science. 2007; 317:1881-1886. [PubMed: 17901324] c) Hagmann WK. J. Med. Chem. 2008; 51:4359-4369. [PubMed: 18570365] 
[5]. For examples of electrophilic $\alpha$-trifluoromethylation methods, see: a) Umemoto T, Ishihara S. J. Am. Chem. Soc. 1993; 115:2156-2164.; b) Blazejewski J-C, Wilmshurst MP, Popkin MD, Wakselman C, Laurent G, Nonclercq D, Cleeren A, Ma Y, Seoc H-S, Leclercq G. Bioorg. Med. Chem. 2003; 11:335-345. [PubMed: 12517429] ; c) Kieltsch I, Eisenberger P, Togni A. Angew. Chem. 2007; 119:768-771.; Angew. Chem. Int. Ed. 2007; 46:754-757.; d) Allen AE, MacMillan DWC. J. Am. Chem. Soc. 2010; 132:4986-4987. [PubMed: 20297822] .

[6]. For examples of radical $\alpha$-trifluoromethylation methods, see: a) Cahard D, Ma J-A. J. Fluorine Chem. 2007; 128:975-996.; b) Itoh Y, Mikami K. Org. Lett. 2005; 7:4883-4885. [PubMed: 16235913] ; c) Cahard D, Ma J-A. Chem. Rev. 2004; 104:6119-6146. [PubMed: 15584697] , and references therein; d) Ma J-A, Cahard D. J. Org. Chem. 2003; 68:8726-8729. [PubMed: 14575512] ; e) Miura K, Taniguchi M, Nozaki K, Oshima K, Utimoto K. Tetrahedron Lett. 1990; 31:6391-6394..

[7]. For examples of organometallic $\alpha$-trifluoromethylation methods, including a recent example by the Ando group of an elegant catalytic $\alpha$-trifluormethylation of enolsilanes using $2 \mathrm{~mol} \%$ of $\left[\mathrm{RhCl}\left(\mathrm{PPh}_{3}\right)_{3}\right]$ and one equivalent of diethyl zinc, see: a) Sato K, Tarui A, Omote M, Ando A, Kumadaki I. Synthesis. 2010:1865-1882.; b) Sato K, Yuki T, Yamaguchi R, Hamano T, Tarui A, Omote M, Kumadaki I, Ando A. J. Org. Chem. 2009; 74:3815-3819. [PubMed: 19366204] ; c) Sato K, Yuki T, Yamaguchi R, Hamano T, Tarui A, Omote M, Kumadaki I, Ando A. J. Fluorine Chem. 2008; 129:51-55..

[8]. a) Nicewicz DA, MacMillan DWC. Science. 2008; 322:77-80. [PubMed: 18772399] b) Nagib DA, Scott ME, MacMillan DWC. J. Am. Chem. Soc. 2009; 131:10875-10877. [PubMed: 19722670] c) Shih H-W, Vander Wal MN, Grange RL, MacMillan DWC. J. Am. Chem. Soc. 2010; 132:13600-13603. [PubMed: 20831195]

[9]. For reviews on photoredox catalysis, see: a) Yoon TP, Ischay MA, Du J. Nat. Chem. 2010; 2:527532. [PubMed: 20571569] ; b) Narayanam JMR, Stephenson CRJ. Chem. Soc. Rev. 2011; 40:102-113. [PubMed: 20532341] . For examples of photoredox catalysis, see: c) Ischay MA, Anzovino ME, Du J, Yoon TP. J. Am. Chem. Soc. 2008; 130:12886-12887. [PubMed: 18767798] ; d) Narayanam JMR, Tucker JW, Stephenson CRJ. J. Am. Chem. Soc. 2009; 131:8756-8757. [PubMed: 19552447] ; e) Koike T, Akita M. Chem. Lett. 2009; 38:166-167.; f) Ischay MA, Lu Z, Yoon TP. J. Am. Chem. Soc. 2010; 132:8572-8574. [PubMed: 20527886] ; g) Andrews SR, Becker JJ, Gagne MR. Angew. Chem. 2010; 122:7432-7434.; Angew. Chem. Int. Ed. 2010; 49:7274-7276.; h) Tucker JW, Narayanam JMR, Krabbe SW, Stephenson CRJ. Org. Lett. 2010; 12:368-371. [PubMed: 20014770] ; i) Condie AG, González-Gómez JC, Stephenson CRJ. J. Am. Chem. Soc. 2010; 132:1464-1465. [PubMed: 20070079] ; j) Tucker JW, Nguyen JD, Narayanam JMR, Krabbe SW, Stephenson CRJ. Chem. Commun. 2010; 46:4985-4987.; k) Furst L, Matsuura BS, Narayanam JMR, Tucker JW, Stephenson CRJ. Org. Lett. 2010; 12:31043107. [PubMed: 20518528] ; 1) Neumann M, F ldner S, König B, Zeitler K. Angew. Chem. 2011; 123:981-985.; Angew. Chem. Int. Ed. 2011; 50:951-954.; m) Lu Z, Shen M, Yoon TP. J. Am. Chem. Soc. 2011; 133:1162-1164. [PubMed: 21214249] ; n) Dai C, Narayanam JMR, Stephenson CRJ. Nat. Chem. 2011; 3:140-145. [PubMed: 21258387] ; o) Rueping M, Vila C, Koenigs RM, Poscharny K, Fabry DC. Chem. Commun. 2011; 47:2360-2362.; p) Nguyen JD, Tucker JW, Konieczynska MD, Stephenson CRJ. J. Am. Chem. Soc. 2011; 133:4160-4163. [PubMed: 21381734] . For reviews of synthetic applications for non-visible light mediated photocatalyzed processes, see: q) Fagnoni M, Dondi D, Ravelli D, Albini A. Chem. Rev. 2007; 107:2725-2756. [PubMed: 17530909] ; r) Griesbeck AG, Hoffmann N, Warzecha K-D. Acc. Chem. Res. 2007; 40:128-140. [PubMed: 17256976] , and references therein.

[10]. For synthetic accessibility of enolsilanes, see: a) Yu J-Q, Wu H-C, Corey EJ. Org. Lett. 2005; 7:1415-1417. [PubMed: 15787520] ; b) Denmark SE, Beutner GL, Wynn T, Eastgate MD. J. Am. Chem. Soc. 2005; 127:3774-3789. [PubMed: 15771512] . For a review of enolsilane reactivity, see: Kobayashi S, Sugiura M, Kitagawa H, Lam WW-L. Chem. Rev. 2002; 102:22272302. [PubMed: 12059268] .

[11]. A sacrificial amine source is required to initiate the photoredox catalytic cycle through our proposed reductive quenching mechanism.

[12]. a) Juris A, Balzani V, Barigelletti F, Campagna S, Belser P, von Zelewsky A. Coord. Chem. Rev. 1988; 84:85-277.b) Kalyanasundaram K. Coord. Chem. Rev. 1982; 46:159-244.

[13]. Schmittel M, Kelly M, Burghart A. J. Chem. Soc. Perkin Trans. 1995; 2:2327-2333. 
[14]. In contrast to the examples in Ref. [8], the standard redox potential of silyl enol ethers $\left(E_{\mathrm{P}}=\right.$ $1.03-1.26 \mathrm{~V}$ vs. SCE in MeCN) is much higher than that of enamines $\left(E_{\mathrm{p}}=0.36-0.60 \mathrm{~V}\right.$ vs. SCE in $\mathrm{MeCN})$. Therefore, the reduction of $*\left[\mathrm{Ru}-(\mathrm{bpy})_{3}\right]^{2+}\left(E_{1 / 2 \mathrm{red}}=0.79 \mathrm{~V}\right.$ vs. SCE in MeCN) is thermodynami-cally disfavored and no reaction was observed for this system. The redox values for enolsilane ${ }^{[14 a]}$ and enamine ${ }^{[14 b]}$ can be found in the following references: a) Audebert P, Roche M, Bekolo H. J. Electroanal. Chem. 1998; 445:203-209.; b) Scholler WW, Niemann J. J. Chem. Soc. Perkin Trans. 1998; 2:369-373..

[15]. a) DeLaive PJ, Sullivan BP, Meyer TJ, Whitten DG. J. Am. Chem. Soc. 1979; 101:4007-4008.b) Anderson CP, Salmon DJ, Meyer TJ, Young RC. J. Am. Chem. Soc. 1977; 99:1980-1982.c) Chen J-M, Ho TI, Mou C-Y. J. Phys. Chem. 1990; 94:2889.d) see also ref. [9a]

[16]. We assume that the reaction between silylketene acetals or $\mathrm{N}, \mathrm{O}$-acetals and $\mathrm{CF}_{3} \mathrm{I}$ occurs via a photoinduced charge-transfer, wherein SET from the acetal to $\mathrm{CF}_{3} \mathrm{I}$ induces $\mathrm{C}-\mathrm{I}$ bond reduction and corresponding $\mathrm{CF}_{3}$ radical formation coinciding with formation of a silyloxy radical cation. This type of mechanism has been proposed for similar electron-rich systems; a) Cho DW, Lee HY, Oh SW, Choi JH, Park HJ, Mariano PS. J. Org. Chem. 2008; 73:4539-4547. [PubMed: 18494523] ; b) Fukuzumi S, Fujita M, Otera J. J. Org. Chem. 1993; 58:5405-5410.; c) Patz M, Fukuzumi S. J. Phys. Org. Chem. 1997; 10:129-137.; d) Cantacuz ne D, Dorme R. Tetrahedron Lett. 1975; 16:2031-2034.. 


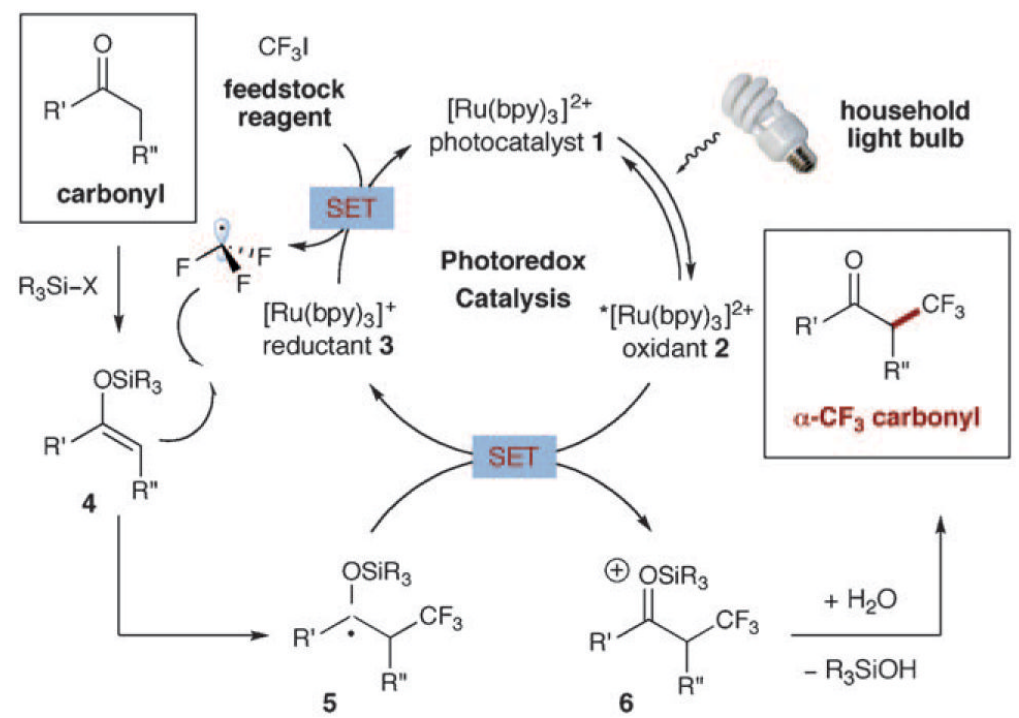

Scheme 1.

Proposed mechanism for carbonyl $\alpha$-trifluoromethylation. 
Table 1

Trifluoromethylation of enolsilanes: initial studies.

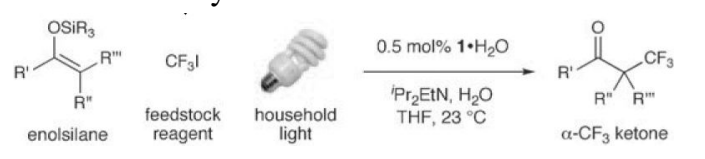

\begin{tabular}{|c|c|c|c|}
\hline Entry & $\mathrm{SiR}_{3}^{[a]}$ & Variation from above conditions & Yield [\%] \\
\hline 1 & TBS & none & 35 \\
\hline 2 & TBS & no light & 0 \\
\hline 3 & TBS & no photocatalyst & $<1$ \\
\hline 4 & TBS & no base & $<1$ \\
\hline 5 & TBS & $+\mathrm{H}_{2} \mathrm{O}^{[b]}$ & 45 \\
\hline 6 & TBS & $+\mathrm{H}_{2} \mathrm{O}^{[b]}$ in $\mathrm{THF}^{[c]}$ & 53 \\
\hline 7 & TIPS & $+\mathrm{H}_{2} \mathrm{O}^{[b]}$ in $\mathrm{THF}^{[c]}$ & 84 \\
\hline 8 & TIPS & $+\mathrm{H}_{2} \mathrm{O}^{[b]}$ in $\mathrm{THF}^{[c]}+i \mathrm{Pr}_{2} \mathrm{NEt}^{[b]}[d]$ & 94 \\
\hline \multicolumn{4}{|c|}{ [a] ${ }^{\text {TBS: tert-butyldimethylsilyl; TIPS: triisopropylsilyl. }}$} \\
\hline \multicolumn{4}{|c|}{$[b] 1.5$ equivalents. } \\
\hline \multicolumn{4}{|c|}{$[c]$ THF used instead of DMF. } \\
\hline
\end{tabular}


Table 2

Trifluoromethylation of enolsilanes: ketone scope.

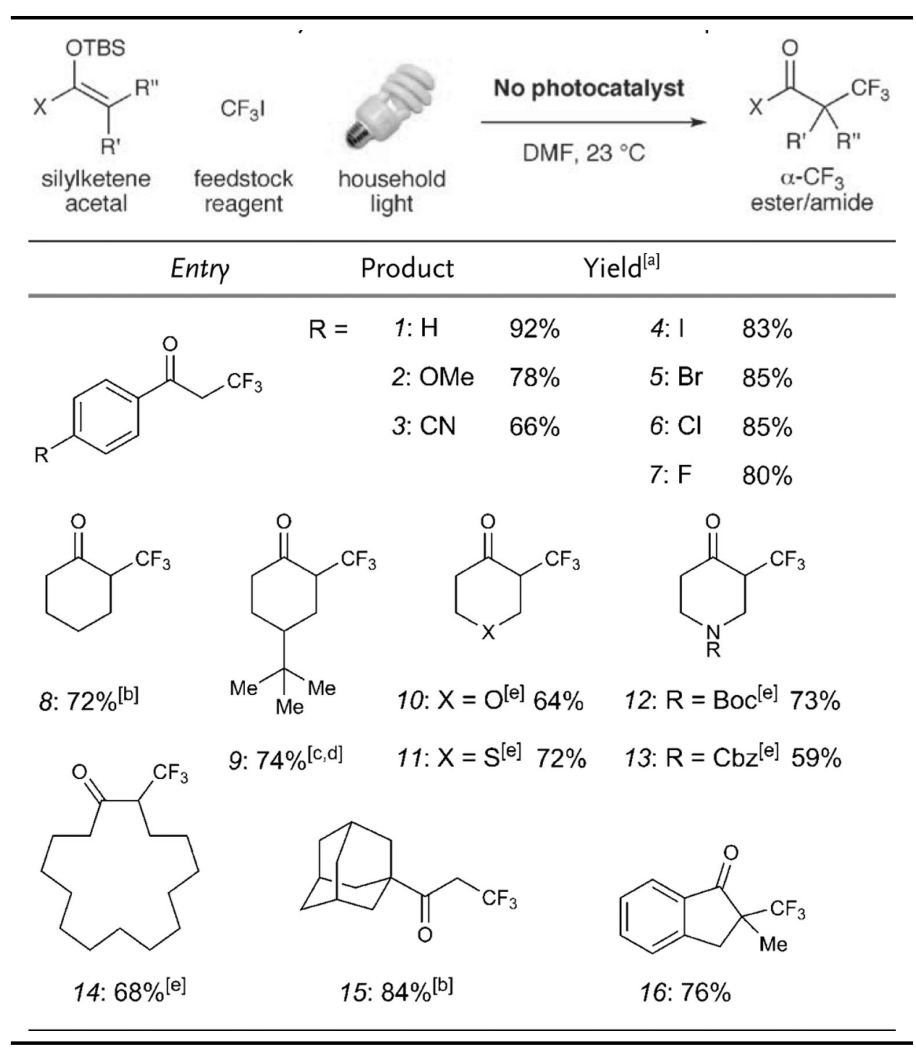

${ }^{[a]}$ Yield of isolated product; $\mathrm{SiR}_{3}=$ TIPS unless otherwise noted.

${ }^{[b]}$ TES ether employed.

${ }^{[c]}$ TBS ether employed.

$\left.{ }^{[d]}\right]_{2.2: 1 \text { d.r. }}$

${ }^{[e]}$ With $\mathrm{NaHCO}_{3}$ in $\mathrm{MeCN}$ and TES ether. 
Table 3

Trifluoromethylation of enolsilanes: esters and amides.

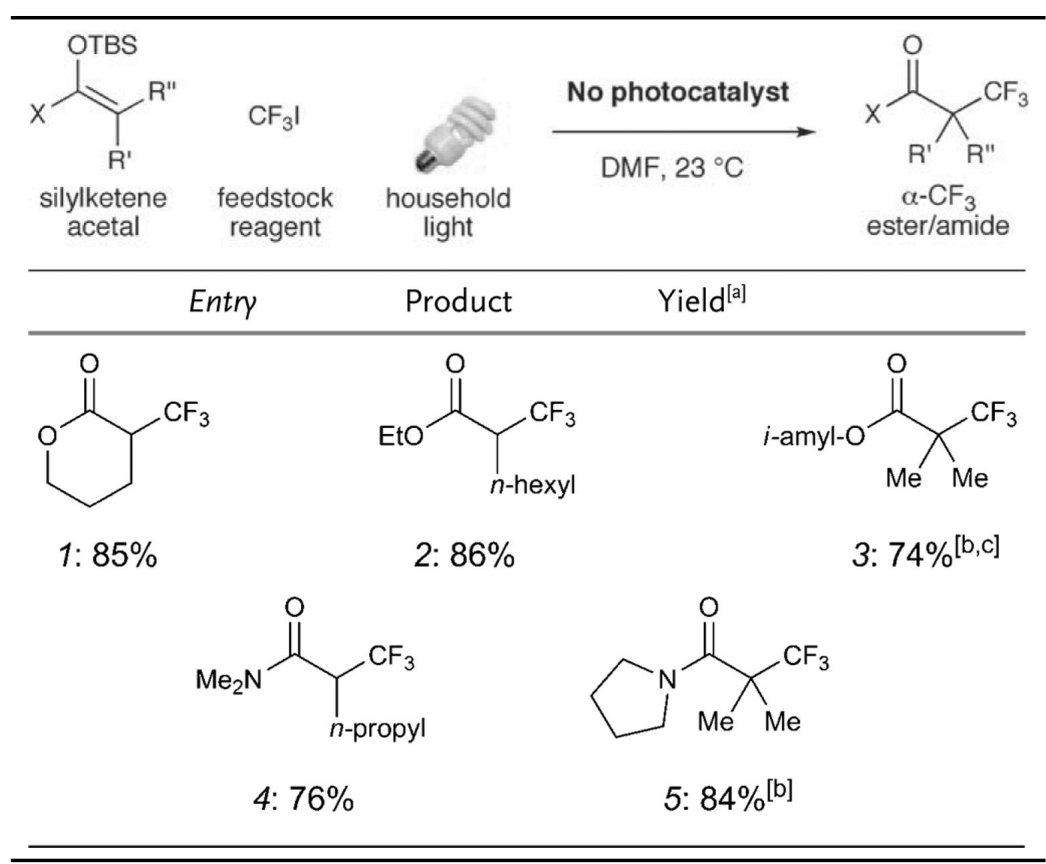

\footnotetext{
${ }^{[a]}$ Yield of isolated products.

${ }^{[b]} 0.5 \mathrm{~mol} \% \mathbf{1} \cdot \mathrm{H}_{2} \mathrm{O}, \mathrm{Et}_{3} \mathrm{~N}$, isoamyl alcohol employed.

${ }^{[a]}$ In MeCN.
} 
Table 4

Direct, one-pot a-perfluoroalkylation of carbonyl compounds.

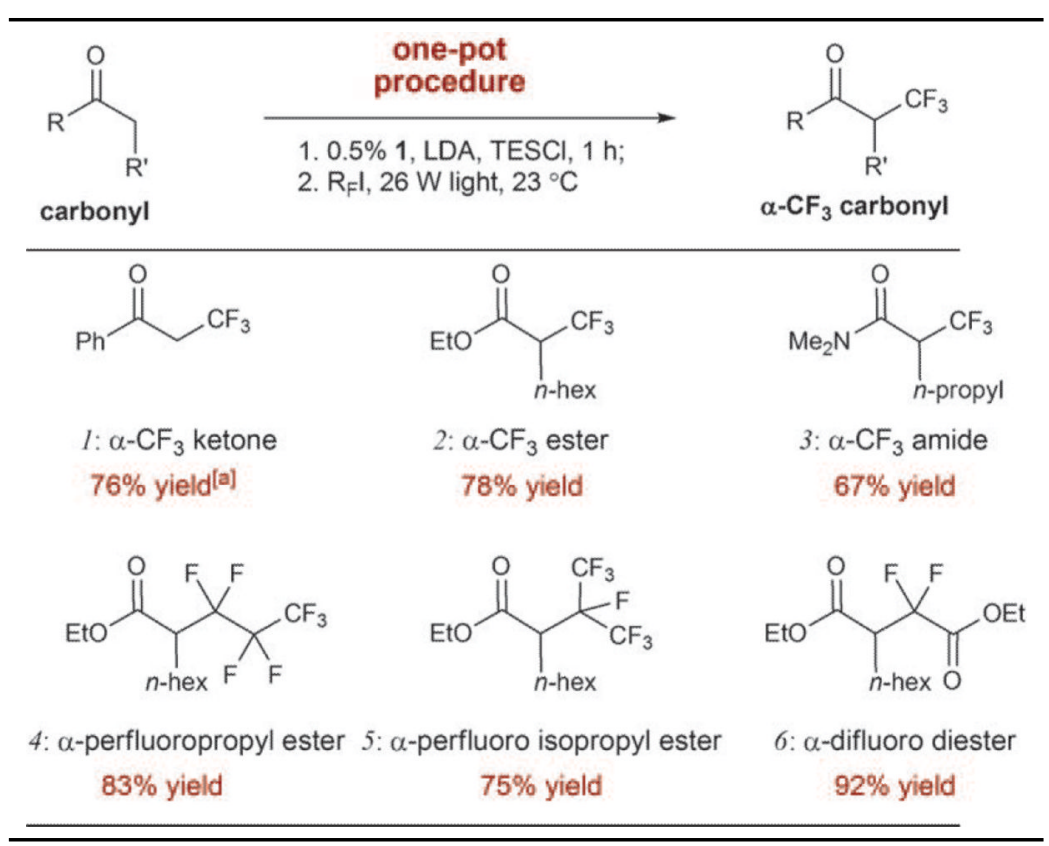

${ }^{[a]}$ TBSOTf, $i \operatorname{Pr} 2$ EtN used instead of TESCl, LDA. 